\title{
Como recompensar e estimular o trabalho de revisão de artigos científicos?
}

\author{
Cristina Muccioli, Mauro Campos, Mauro Goldchmit, Paulo E.C. Dantas, Samir J. Bechara, Vital Paulino Costa
}

Por meio de um forum eletrônico, a World Association of Medical Editors (WAME), entidade sem fins lucrativos, que congrega Editores de revistas científicas do mundo inteiro, propõe-se a discutir com editores científicos do mundo inteiro das mais variadas especialidades médicas, temas referentes à editoração, coordenação, revisão e aprovação de artigos científicos; enfim, do trabalho de editoração de uma revista científica e suas implicações. Dada à universalidade de opiniões, geralmente expressa a atualidade e importância dos assuntos discutidos.

Um dos pontos mais discutidos recentemente diz respeito à forma de manter a atividade de revisão de artigos científicos feitas por pares, atrativa, rápida e com alto padrão de qualidade.

Há um consenso dentre os participantes deste fórum de que a maioria dos revisores selecionados aceita fazer revisão de artigos científicos de maneira gratuita por senso de responsabilidade para com seus pares, para o desenvolvimento e encorajamento de novas pesquisas e pesquisadores e por razões acadêmicas. Outro fator que atrairia o revisor seria o reconhecimento intelectual de seu trabalho.

Como em qualquer lugar, existem aqueles revisores que se destacam pela qualidade empregada na revisão; outros, pela velocidade e pelo volume de revisões feitas no ano. Entretanto, outros pecam em cumprir as obrigações relacionadas às tarefas mínimas relacionadas com o processo de revisão. Em vista disso, com o auxílio da WAME, uma forma de criar um ranking com critérios para avaliação dos revisores existentes e para a seleção de novos.

O esquema é simples e, na verdade, já é aplicado em dezenas de revistas científicas do mundo inteiro (com algumas adaptações para a nossa realidade):

- Haveria uma análise da atuação de cada revisor por períodos regulares (anualmente, por exemplo);

- Aquele que obtivesse uma pontuação (score) consistente de 1 e 2, seria excluido da lista de revisores;

- Aquele que obtivesse uma pontuação (score) entre 3 e 3,5, receberia correspondência da Editoria (carta ou e-mail), notificando-o de sua situação e solicitando melhorias na revisão;

- Scores superiores a 4 , receberiam correspondência de agradecimento e elogio.

- Scores superiores a 4, com alto volume de revisões anuais e pontualidade no cumprimento dos prazos, rece- beriam a correspondência e fariam parte da Nominata na última edição do ano. Poderiam participar como palestrantes em nossos cursos dos ABOs nos Congressos Brasileiros, fariam parte do Corpo Editorial no ano subsequiente e seriam sérios candidatos a Editores Associados, quando da renovação dessa função

Os elementos usados na avaliação das revisões e revisores (Scoring Elements for Quality of Reviews) seriam os seguintes:

- O revisor identifica e comenta sobre os pontos fortes e fracos do desenho do estudo e seu método?

- O revisor comenta de maneira acurada e produtiva sobre a qualidade da interpretação dos dados, incluindo o reconhecimento das limitações do estudo?

- O revisor comenta sobre pontos fortes e fracos do manuscrito em si (coerência, gramática e vernáculo), independente do desenho, método, resultados e interpretação do estudo?

- O revisor provê sugestões que melhorem a qualidade do manuscrito;

- Os comentários do revisor aos autores são construtivos e profissionais?

- O revisor provê ao Editor e Editores Associados suficiente informação para a tomada de decisão em aceitar ou não o manuscrito?

Definição da pontuação (Score Definitions)

$1=$ Conteúdo da revisão inaceitável e fraco;

2= Conteúdo da revisão inaceitável e fraco

3= Aceitável

$4=$ Bom

5= Excepcional, difícil de melhorar

(10-20\% das revisões, no máximo)

Um ranking anual dos melhores revisores formaria uma massa crítica de revisores seniors que seriam candidatos ao Corpo Editorial num futuro próximo.

Enfatizamos que a atividade de revisão de artigos científicos é uma atividade intelectual crucial para o desenvolvimento da ciência e tecnologia e deve ser sempre reconhecida. Uma revisão cuidadosa e detalhista é tão importante quanto a própria autoria.

Abrimos a discussão aos nossos leitores para analisar, criticar e sugerir modificações a este sistema de avaliação, por meio da secção Carta ao Editor. Todas serão muito apreciadas! 